\title{
Analysis of Planar E+l and ER+l Transformers for Low-Voltage High-Current DC/DC Converters with Focus on Winding Losses and Leakage Inductance
}

Pittini, Riccardo; Zhang, Zhe; Ouyang, Ziwei; Andersen, Michael A. E.; Thomsen, Ole Cornelius

Published in:

Proceedings of The International Power Electronics and Motion Control Conference (IPEMC)

Link to article, DOI:

10.1109/IPEMC.2012.6258778

Publication date:

2012

Document Version

Publisher's PDF, also known as Version of record

Link back to DTU Orbit

Citation (APA):

Pittini, R., Zhang, Z., Ouyang, Z., Andersen, M. A. E., \& Thomsen, O. C. (2012). Analysis of Planar E+l and ER+I Transformers for Low-Voltage High-Current DC/DC Converters with Focus on Winding Losses and Leakage Inductance. In Proceedings of The International Power Electronics and Motion Control Conference (IPEMC) (pp. 488-493). IEEE. https://doi.org/10.1109/IPEMC.2012.6258778

\section{General rights}

Copyright and moral rights for the publications made accessible in the public portal are retained by the authors and/or other copyright owners and it is a condition of accessing publications that users recognise and abide by the legal requirements associated with these rights.

- Users may download and print one copy of any publication from the public portal for the purpose of private study or research.

- You may not further distribute the material or use it for any profit-making activity or commercial gain

- You may freely distribute the URL identifying the publication in the public portal 


\title{
Analysis of Planar E $+\mathrm{I}$ and $\mathrm{ER}+\mathrm{I}$ Transformers for Low-Voltage High-Current DC/DC Converters with Focus on Winding Losses and Leakage Inductance
}

\author{
Riccardo Pittini, Zhe Zhang, Ziwei Ouyang, Michael A. E. Andersen, Ole C. Thomsen \\ Department of Electrical Engineering, Technical University of Denmark, Kgs. Lyngby, Denmark \\ Email: ripit@elektro.dtu.dk
}

\begin{abstract}
In this paper an analysis of two planar transformers designed for high-current switching applications is presented. Typical converter application is represented by fuel and electrolyser cell converters. The transformer designs are based on $E+I$ and $E R+I$ planar cores while the analysis focuses on winding resistance and leakage inductances which represent the main concerns related to low-voltage high-current applications. The PCB winding design has a one to one turn ratio with no interleaving between primary and secondary windings. The main goal was to determine if ER planar core could provide a significant advantage in terms of winding losses compared to planar E cores. Results from finite element analysis highlight that low frequency winding resistance is lower for the ER core since it is dominated by the lower mean turn length however, as the AC-resistance becomes dominating the winding eddy current losses increases more in the ER core than in the $E$ core design. Calculated and simulated leakage inductances for the analyzed cores do not show relevant differences. A laboratory prototype based on E64 planar core is used as reference. Laboratory measurements highlight that FEM analysis provides more realistic results when computing the winding AC-resistance.
\end{abstract}

Keywords - Planar Magnetics, Transformer Parasitics, DC/DC Switching Converters, High-Current.

\section{INTRODUCTION}

As renewable energies are getting more important, power electronics converter are becoming more diffused and are demanded to operate in more critical applications. Non isolated Switch Mode Power Supplies (SMPS) are a limited in their applications and transformer based SMPS can provide several advantages in terms of safety (input to output isolation), reducing the component stresses (e.g. minimizing voltage and current peaks) and flexibility since they can provide easily multiple outputs and voltage regulation (turn ratio selection). Their main disadvantage is to introduce additional cost, losses and increase the volume and converter weight. The main drawbacks of transformer based SMPS are highly compensated by their advantages, therefore the market of wounded components is growing in parallel to the power supplies market [1]

Many efforts have been performed for reducing the cost and the size of magnetic components in power supplies [2] and planar structure provides an excellent solution for magnetic components into SMPS. In fact, in planar transformers windings have a flat structure commonly made with Printed Circuit Board (PCB) layers or copper foils [3]; PCB windings are easily integrated in mass production reducing costs and giving a low-profile high-power density structure. The natural flatness of the winding cross section is more suitable for operation at high frequencies since it is less sensible to skin effect compared to traditional wires, moreover, the leakage inductance can be significantly reduced by heavy interleaving [4][5][6][7] compared to traditional wounded components. The main disadvantages of planar transformers comes from their high capacitive coupling between the windings [8], difficulties for designing high voltage due to limited clearance and creepage distances, and challenging high current designs since it is difficult to laminate thick copper tracks on PCB. In some applications it is desirable to operate at low-voltage and high-current (e.g. fuel cells [9][10]) and as the converter power ratings increase the design of highcurrent planar transformers based PCB windings becomes more and more challenging. Most of the previous research on high-current low-voltage transformers focuses on conventional high-power and wounded transformers moreover, a limited number of publications were found on high-current planar transformers [11][12] highlighting that the topic requires further investigations and analysis for determining which are the most suitable cores for these applications.

The selected application is a transformer for a full bridge isolated boost converter which represents one of the most suitable topologies for high-current and low-voltage applications with wide input voltage window. This paper will present an analysis of two planar cores, E64/10/50 and ER64/13/51, aiming to highlight which is the most suitable core in terms of winding losses and leakage inductance for high current planar transformers. Since the most suitable core is application and topology dependant, the paper will not state which is the best core, however, will give a clear picture of the differences in terms of stray parameters when the two selected cores are used for designing high current planar magnetic. Analytical and finite element analysis results are compared with a laboratory prototype. 


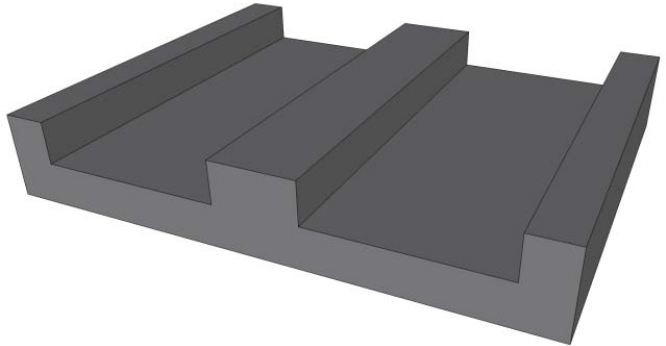

(a)

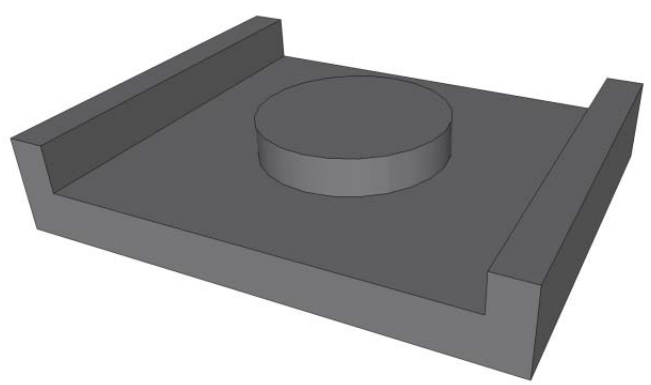

Fig. 1. Planar transformer cores used in the analysis, E64/10/50 (a) and ER64/13/51 (b)

\section{Selected Planar Cores}

As general rule, rounded core cross section transformers are preferred in many applications due to their lower mean turn length and leakage inductance. However, round core cross section transformers might not be the best for all applications and selecting the best core for the candidate application might not be straight forward but, it would require more design and optimisation cycles for different core shapes.

In planar transformers for high current applications the smaller winding area width can represent significant issue in terms of increased winding resistance, in fact a winding resistance of few $\mathrm{mOhm}$ at high current (e.g. 50-100 A) can easily produce power losses in the range of tenths of Watt and more. For this reason to verify the possible advantages and disadvantages of rounded core planar transformers requires an accurate analysis of different transformer designs.

The two selected cores for the analysis are E64/10/50 and ER64/13/51 from Ferroxcube in 3F3 material, Fig. 1. The cores have been selected since they have similar effective area and minimum area; their base footprint is the same $(64 * 50.8 \mathrm{~mm})$ however, their main difference is in their height that differs by $\sim 3 \mathrm{~mm}$ giving a substantial difference in the

TABLE I. SELECTED CORE CHARACTERISTICS

\begin{tabular}{llll}
\hline \multicolumn{1}{c}{ Core Type } & E64/10/50 & ER64/13/51 & \multicolumn{1}{c}{ ER64/10/51 } \\
Material & $3 \mathrm{~F} 3$ & $3 \mathrm{~F} 3$ & $3 \mathrm{~F} 3$ \\
Effective area $\left[\mathrm{mm}^{2}\right]$ & 519 & 566 & 566 \\
Effective volume $\left[\mathrm{mm}^{3}\right]$ & 40700 & $52600^{\text {a }}$ & $\sim 43700$ \\
Effective length $[\mathrm{mm}]$ & 79.9 & 93 & $\sim 80$ \\
Core min area $\left[\mathrm{mm}^{2}\right]$ & 519 & 507 & 507 \\
Core mass $[\mathrm{g}]$ & $\sim 100$ & $\sim 152$ & $\sim 125$ \\
Gapped & No & No & No \\
\hline \multicolumn{3}{r}{ a. Volume difference is due to the different core height. }
\end{tabular}

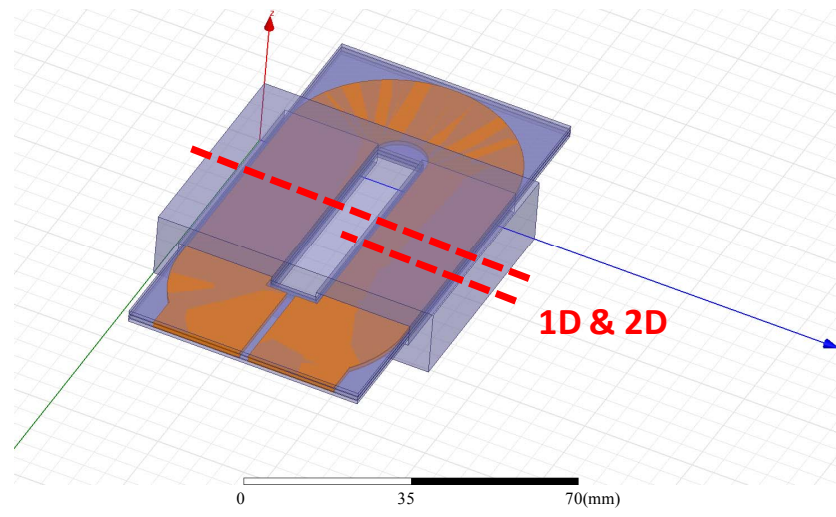

Fig. 2. Planar transformer E64/10/50 core, 3D model with high current winding: highlight axes used in $1 \mathrm{D} \& 2 \mathrm{D}$ analysis.

core volume. For this reason for obtaining a better trustworthy analysis the ER64/13/51 core height has been clipped to $10.2 \mathrm{~mm}$ obtaining an ER64/10/51. The cores main characteristics as specified from the manufacturer are summarized in Table I.

\section{METHODOLOGY}

It is essential that the method used to analyze the two transformers is coherent, therefore, for performing a more trustworthy analysis purely based on the transformer core geometry and not on the winding topology, a simple PrimarySecondary (P-S) winding topology has been considered. More complicated winding arrangements can be designed however, this is not in the scope. The high current primary windings on Fig. 2 and Fig. 3 were designed for using the maximum available winding area width in order to reduce as much as possible the winding resistance since it is the most critical factor regarding integration of high current tracks on PCB. In the ER core the winding width was selected as in the E core case however, due to geometrical limitations of the ER core the winding width was reduced in proximity of the core centre, as visible in Fig. 6. The same creepage and clearance constrains were used for designing the transformer windings.

\section{A. Analytical Approach}

Analytical approach is often performed considering core

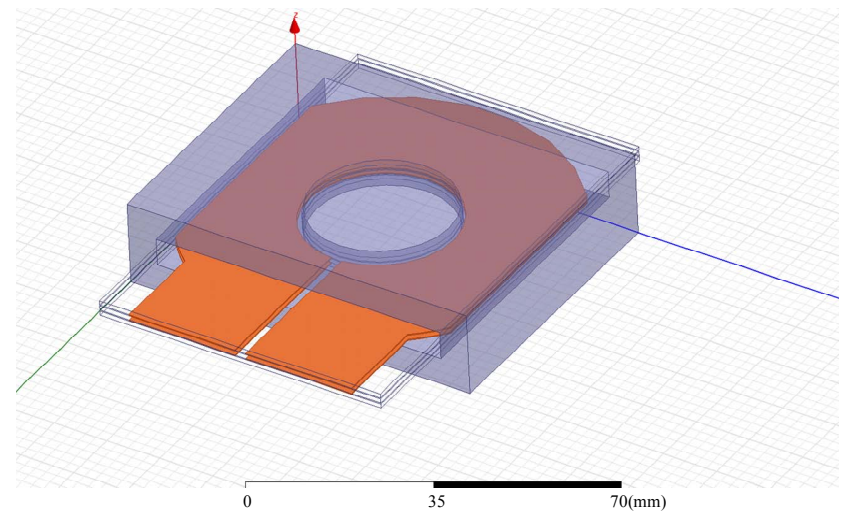

Fig. 3. Planar transformer ER64 core, 3D model with visible high-current winding geometry. 


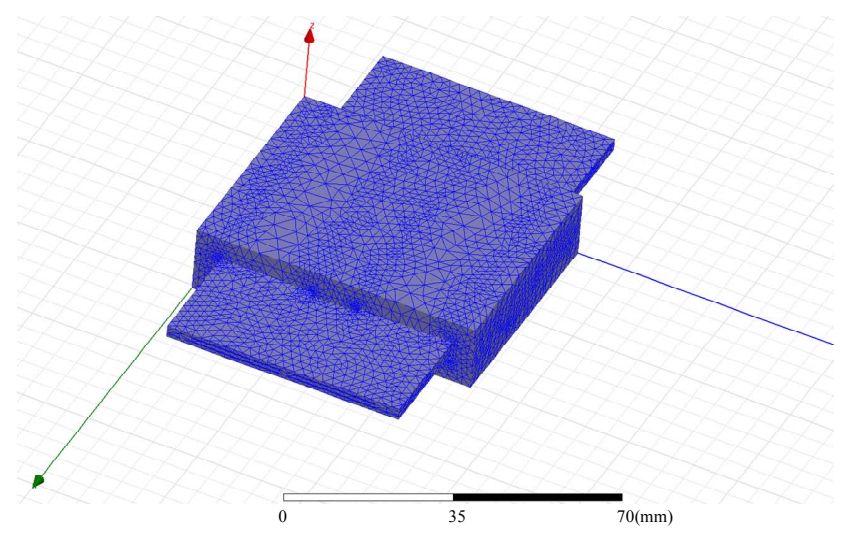

Fig. 4. Example of a planar transformer based on E64/10/50, 1:1 turns ratio, modeled with 3D FEM

symmetries to simplify the analytical expressions, 1-D or 2-D as in Fig. 2; this allows to easily calculate the main stray parameters in planar transformers.

In planar transformers the windings consist of parallel and flat conductors creating a parallel plane capacitor structure. In this type of transformers the intra-winding capacitance can often be neglected due to the dominating primary-secondary winding capacitance. This capacitance can be the main issue for common mode noise and it can be simply estimated as (1) [4].

$$
C_{i}=\varepsilon_{0} \varepsilon_{r} \frac{(l+4 b \cdot i)}{h_{\Delta}} \quad(i=1,2,3 \ldots, n)
$$

Where $\varepsilon_{0}$ is the permittivity in free space, $\varepsilon_{r}$ is the relative permittivity of the insulating material, $l$ is the length of the center leg cross-section, $b$ is the conductor width, $h_{\Delta}$ is the distance between the conductive plates and $n$ is the number of overlapping turns.

The most used analytical approach for estimating the winding leakage inductance considers the energy stored in the transformer windings. From the transformer winding generic expression of the leakage inductance can be extracted as in (2) [4]

$$
L_{i k}=\mu_{0} \frac{l_{w}}{b_{w}} \frac{N^{2}}{M^{2}}\left(\frac{\sum x}{3}+\sum x_{\Delta}\right)
$$

Where $\mu_{0}$ is the permeability, $l_{w}$ is the length of one turn, $b_{w}$ is the width of each turn, $N$ is the number of turns on the winding which the leakage inductance is to be referred, $M$ is the number section interfaces, $\sum x$ is the sum of all section layer heights (windings) and $\sum x_{\Delta}$ is the sum of all intersection layer heights (insulator). This approach computes the leakage inductance considering the magneto motive force (MMF) linear between non-interleaved sections. Therefore, the approach provides identical leakage inductance values for different winding arrangement (e.g. P-P-S-S-S-S-P-P provides the same leakage inductance as P-P-S-S-P-P-S-S considering the same insulation thickness). Inaccuracies due to this approach can be reduced by using a piecewise linear approach described and proven in [3]. However, in this paper the most diffused methodology is used for comparison with FEM methodology.

For a simple two winding topology as in the selected case scenario $(\mathrm{P}-\mathrm{S})$ with only one interface layer between primary and secondary the leakage inductance can be estimated with (3) $[4]$.

$$
L_{i k}=\mu_{0} \frac{l_{w}}{b_{w}} N^{2}\left(\frac{h_{1}+h_{2}}{3}+h_{\Delta}\right)
$$

Where $h_{1}$ and $h_{2}$ are the heights of the primary and secondary windings respectively, $h_{\Delta}$ is the height of the insulation layer between the primary-secondary traces. Winding losses represent the main concern regarding high current integrated magnetics; in a transformer the skin effect and the proximity effect strongly influences the Joule losses especially at high switching frequencies. Planar transformers have the advantage of having flat conductors which sensibly reduces the sensitivity to skin effect. Proximity effect is caused by current flowing in adjacent conductors, also this effect contributes to increase the conductor AC-resistance moreover, and the proximity effect can dominate over the skin effect. The ratio between the AC-resistance and the DC-resistance that takes into account the skin and proximity effects can be expressed as in (4) [4].

$$
\begin{aligned}
& \frac{R_{a c}}{R_{d c}}=\frac{\xi}{2}\left[\frac{\sinh (\xi)+\sin (\xi)}{\cosh (\xi)-\cos (\xi)}\right. \\
& \left.+(2 \mathrm{~m}-1)^{2} \frac{\sinh (\xi)-\sin (\xi)}{\cosh (\xi)+\cos (\xi)}\right]
\end{aligned}
$$

Where $\xi=\mathrm{h} / \delta, \mathrm{h}$ is the conductor height, $\delta$ is the skin depth in the conductor and $m$ is $>1$ for non interleaved multilayer windings.

\section{B. FEM Analysis (FEA)}

Finite Element Method (FEM) can be used for calculating transformer characteristics and stray parameters. FEM can be performed based on two different approaches:

- 2-D approach

- 3-D approach

2-D simulations perform an analysis on the transformer based on its symmetry axes. The simulation can be performed on the entire transformer cross section or only on half of it considering its symmetry, as shown on Fig. 2. This approach requires limited computation time however it can only partially consider the flux linkage in free air (without end effects) since it cannot take into account that the core geometry is limited. 

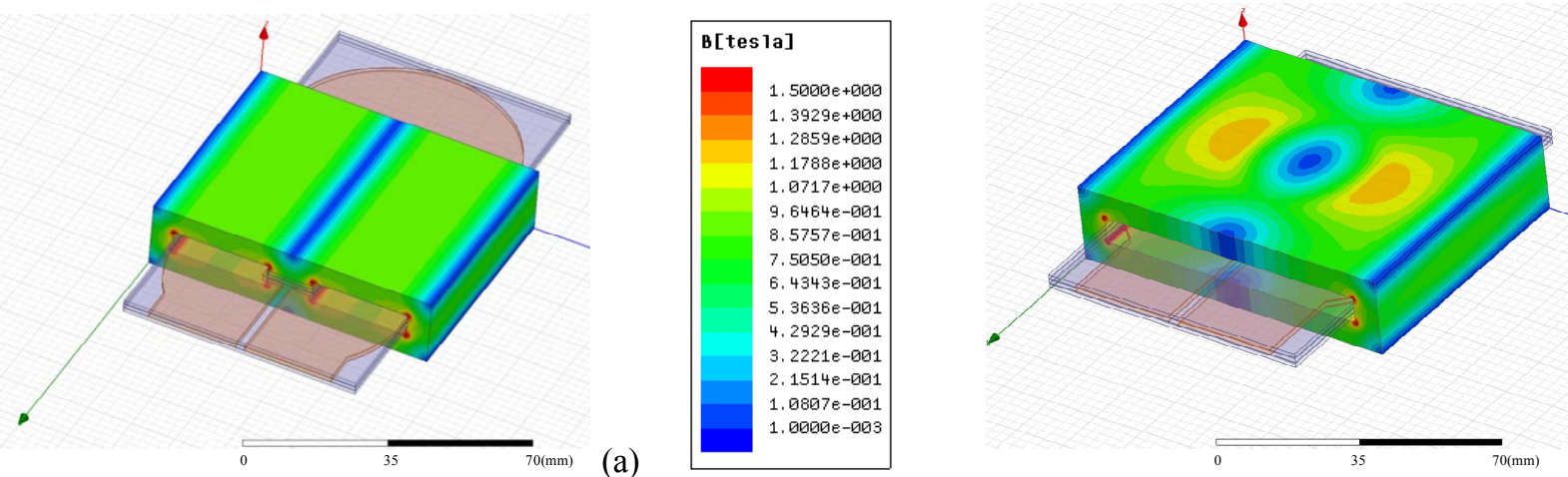

(b)

Fig. 5. Magnetic flux in the $\mathrm{E}+\mathrm{I}$ core transformer (a) and in the $\mathrm{ER}+\mathrm{I}$ core transformer (b).

3-D approach performs a FEM analysis over the entire transformer model as on Fig. 4. This type of analysis is the most accurate since it computes the transformer parameters considering also part of the windings that is exposed to free air. However, this type of computation requires very long computation times since the entire geometry has to be modelled with a fine mesh. Moreover, when a model is composed by large and small geometries the mesh used for the analysis should be selected properly to achieve the desired analysis accuracy.

\section{Methodology Applied to the ANALysed CASE}

This analysis was performed based on three approaches: analytical, 3D FEM and experimental. Since performing an accurate analytical analysis of a complex geometry requires geometrical simplifications especially when modelling rounded geometries, a simple case analysis is selected. The transformer is specified to have a 1 to 1 turn ratio and a simple P-S structure with no interleaving, Table II. The analysis focused on determining the AC-resistance and the leakage inductance for the two proposed geometries and comparing the obtained values with analytical calculations and laboratory measurements on a prototype.

An adequate analytical analysis of the rounded cross section planar core has to consider minimal geometrical

TABLE II. TRANSFORMER SPECIFICATIONS

\begin{tabular}{lcc}
\hline \multicolumn{1}{c}{ Core Type } & E+I 64/10/50 & ER+I 64/10/51 \\
Material & $3 \mathrm{~F} 3$ & $3 \mathrm{~F} 3$ \\
Material relative permeability $\left(\mu_{r}\right)$ & 1760 & 1760 \\
Transformer turn ratio & $1: 1$ & $1: 1$ \\
Winding structure & $\mathrm{P}-\mathrm{S}$ & $\mathrm{P}-\mathrm{S}$ \\
Primary copper thickness $[\mathrm{mm}]$ & 0.2 & 0.2 \\
Secondary copper thickness $[\mathrm{mm}]$ & 0.2 & 0.2 \\
Primary copper width $[\mathrm{mm}]$ & 20 & $20 \sim 11^{\mathrm{b}}$ \\
Secondary copper width $[\mathrm{mm}]$ & 20 & $20 \sim 11^{\mathrm{b}}$ \\
Dielectric material & $\mathrm{FR} 4$ & $\mathrm{FR} 4$ \\
Dielectric thickness $[\mathrm{mm}]$ & 0.8 & 0.8 \\
Temperature $\left[{ }^{\circ} \mathrm{C}\right]$ & 25 & 25 \\
\hline
\end{tabular}

Core volume reduced for having same height/volume as E64.

b. Winding width limited by winding area width. approximations in order to reduce computational errors. It is possible to analyse transformer resistance and leakage inductance with a piece-wise approach which require dividing the winding into several sectors and execute the calculations for each sector. The selected approach considers and equivalent rectangular winding where the winding length is defined by the core mean turn length (MTL) and the winding width by the ratio between the effective surface of the winding and the MTL of the core. The effective winding surface can be easily computed by considering surface of an annulus with width equal to the winding width used in the E64 design and removing to that value the two sector regions highlighted on Fig. 6. The geometrical approach simplifies the computation since avoids performing an analytical analysis for many winding sections.

In the 3D FEM approach the two transformers were designed and simulated with Ansoft Maxwell v15, as shown on Fig. 5 where the magnetic flux for the two analysed cases is plotted on the core surface. Since the complete 3D model for E64 and ER64 core based transformed does not represent a very complex structure to analyse the simulation was defined with a minimum convergence of $0.1 \%$ without requiring too long computation time (also limited by the few analysed frequencies). The FEM simulations allow extracting directly the transformer parameters; both the AC-resistance and the leakage inductance were extracted for different frequency values: $50 \mathrm{~Hz}$ as low frequency reference and $50-150 \mathrm{kHz}$ as

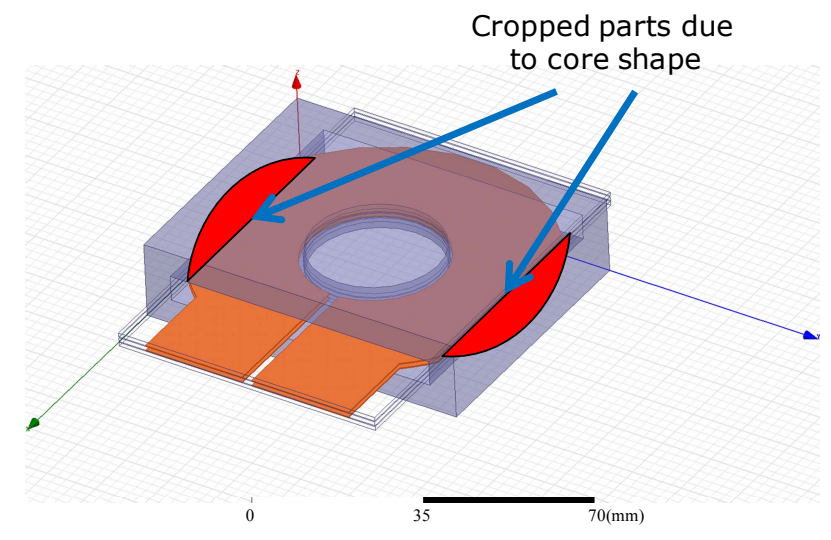

Fig. 6. ER 3D model highlighting (red) cropped winding sectors. 


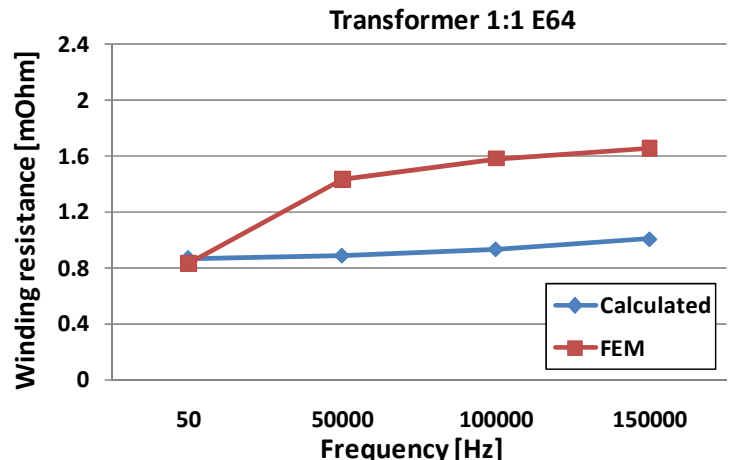

Fig. 7. Comparison of calculated winding resistance and FEM analysis for E64 core, 1:1 turns ratio.

the expected operating frequency range of the power converter. The AC-resistance is extracted from the winding losses, its value at $50 \mathrm{~Hz}$ represents a $\mathrm{DC}$-resistance reference and at 50$150 \mathrm{kHz}$ represents the actual winding resistance (AC). With a similar procedure it is possible to extract the transformer leakage inductance form the sum of the energies stored in the transformer leakage layers. However, since the FEM simulations can provide the transformer coupling matrix $\left(\mathrm{L}_{11}\right.$, $\mathrm{L}_{12}, \mathrm{~L}_{21}$ and $\mathrm{L}_{22}$ ), extracting the leakage inductance from these values is a direct procedure.

The experimental approach has been used for establishing concrete references to validate the analytical computations and the analysis performed in 3D FEM. During the initial phase, the aim was to develop two prototypes that would have been used as reference however, due to the lack of availability of ER64 cores, only a prototype based on E64 core was developed highlighting that the availability of specific core shapes and materials might represent an important issue related to transformer design. The prototype based on E64 core is used to verify that the analytical and FEM approach produce coherent values.

\section{ANALYSIS OF THE RESULTS}

The analysis of the results is divided into two parts: in the first part results from the analytical approach and the FEM analysis are compared, while in the second part the results

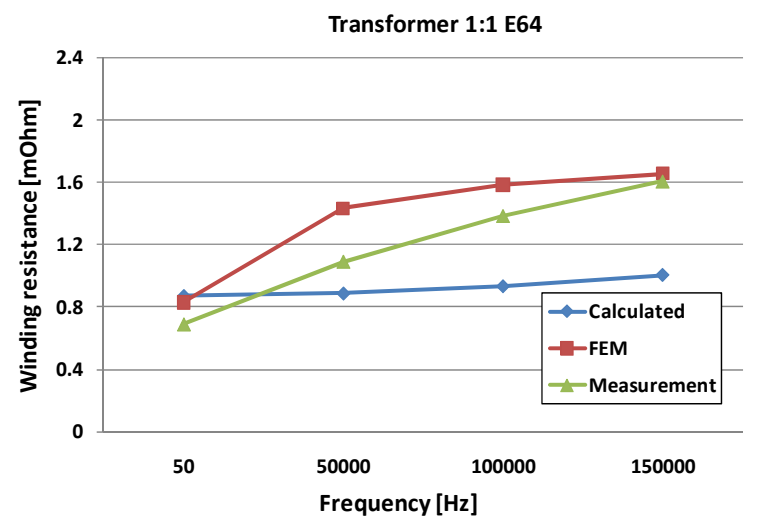

Fig. 9. Comparison of calculated winding resistance, FEM analysis and measurement for E64 core, 1:1 turns ratio.

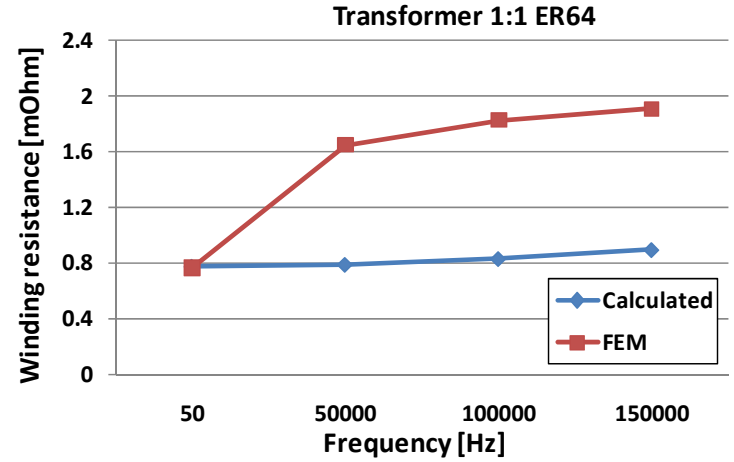

Fig. 8. Comparison of calculated winding resistance and FEM analysis for ER64 core, 1:1 turns ratio

obtained with the laboratory reference prototype are analysed.

The analytical and FEM results are presented on Fig. 7 and Fig. 8, which allow comparing the transformer winding ACresistance: the $\mathrm{E}$ core based transformer has a slightly higher low frequency primary resistance (DC-resistance) compared to the ER solution, this is due to the higher mean turn length of required for the E core windings. Nevertheless, at higher frequencies the AC-resistance significantly increases and becomes dominating for the ER core. The ER core windings width is not constant, in fact winding width is limited by the narrow winding area width in proximity of the core centre while, away from the core centre the width is defined as in the E core case. For the analysed case the proximity effects in the narrow winding area width of the ER core dominate compared to $\mathrm{E}$ core. The calculated resistance at low frequencies matches (DC-resistance) good the FEM analysis however, at high frequencies the mismatch significantly increases highlighting that geometrical approximations and assumptions used in the calculation introduce large inaccuracies (e.g. Dowell's equation (4) considers infinite MLT length and uniform turn current density). The comparison with the reference prototype (Fig. 9) highlights that FEM analysis can produce results which are more realistic compared to analytical calculations based on (4). The relevant differences observed between analysis and measurement can be explained by the prototype accuracy (realised with copper foil and dielectric layers, on Fig. 10), the contact point resistance and the instrument resolution when measuring such low-resistance values.

The leakage inductances referred to the transformer primary are presented on Table III. The two analysed cases show similar leakage inductance at the expected operating frequencies with a slightly higher value for the $\mathrm{E}$ core compared to the ER core in the calculations. The higher mean turn length of the E core is compensated by the wider winding giving comparable leakage inductances for the two designs. The opposite effect is observed on the ER core design, where the limited winding width is balanced by a lower mean turn length. The calculated leakage inductance was evaluated based on geometrical approximation introducing significant approximations, while the FEM analysis provided a difference between the E64 and ER64 core of less than $0.1 \%$ which also 

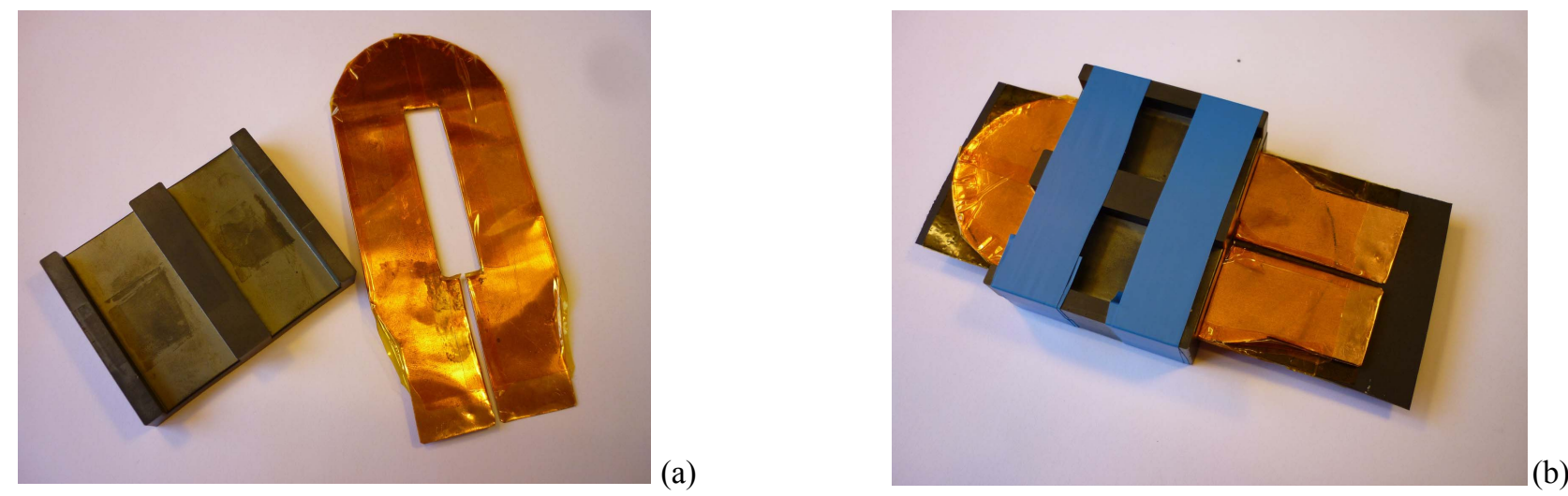

Fig. 10. Pictures of E64 core and realized winding (a) and assembled transformer (b).

is the defined FEM accuracy for convergence. The experimental results have a large deviation from the expected value, in fact the laboratory prototype based on copper foil windings has an insulation layer thickness which is slightly inhomogeneous compared to the designed case, giving a larger measured inductance. Even though, low-inductance Kelvin probes have been used, they introduce significant stray inductance $(\sim<10 \mathrm{nH})$ due to the measuring system which justifies the observed difference.

TABLE III. LEAKAGE INDUCTANCE

\begin{tabular}{lcc}
\hline & Leak_pri $@ 100$ kHz $(\mathbf{n H})$ \\
Calculated & 11.84 & ER-core \\
FEM Analysis & 9.998 & 10.64 \\
Measured & $\sim 22$ & 9.998 \\
\hline
\end{tabular}

\section{CONCLUSIONS}

Designing planar transformers for high current SMPS require analysis and selection of the most suitable core for the selected application. This is not a straight forward choice and it is required a detailed analysis that can be performed as described in this paper. Different analysis can produce significantly different results making the selection of the most application-suitable core even more complicated. The proposed analysis does not define which is the best core (application dependent) however, gives a clear indication for winding losses and leakage inductance on transformers based on planar E or ER cores.

For the selected designs, high current planar transformers based on E cores have shown lower winding losses compared to the ER cores. This effect is observed mainly due to proximity and skin effects which significantly increase the winding resistance in the narrow winding area width of the ER, in fact $\mathrm{E}$ cores are less sensible to this effect since the winding area width is significantly higher than ER cores. In the analysed cases both core designs have shown similar leakage inductance values; differences can be enhanced by increasing the number of turns. Differences observed with the laboratory prototype (leakage inductance) are mainly related to the slightly different and inhomogeneous insulation layer thickness and to stray inductance introduced by the measuring system.

\section{REFERENCES}

[1] Aime, J.; Cogitore, B.; Meunier, G.; Clavel, E.; Maréchal, Y.; "Numerical Methods for Eddy Currents Modeling of Planar Transformers," IEEE Transactions on Magnetics, vol.47, no.5, pp.10141017, May 2011.

[2] Pavlovsky, M.; de Haan, S.; Ferreira, J.A.; , "Reaching High Power Density in Multikilowatt DC-DC Converters With Galvanic Isolation," IEEE Transactions on Power Electronics, vol.24, no.3, pp.603-612, March 2009.

[3] Ziwei Ouyang, "Advances in Planar and Integrated-Magnetics", Danish Technical University, PhD Thesis, ISBN: 978-87-92465-88-7, pages: $228,2011$.

[4] Z. Ouyang; O.C.,Thomsen; M. A. E., Andersen; , "Optimal design and tradeoff analysis of planar transformer in high-power dc-dc converters," IEEE Transactions on Industrial Electronics, vol.59, no.7, July 2012.

[5] Carsten, B.W.; , "The low leakage inductance of planar transformers; fact or myth? ," Applied Power Electronics Conference and Exposition, APEC 2001. Sixteenth Annual IEEE, vol.2, pp.1184-1188 vol.2, 2001.

[6] Jianbing Li; Changchao Hu; Xuemin Pang; , "Analysis of the leakage inductance of planar transformer," 9th International Conference on Electronic Measurement \& Instruments, ICEMI 2009, pp.1-273-1-276, 16-19 Aug. 2009.

[7] Cove, S.R.; Ordonez, M.; Quaicoe, J.E.; , "Modeling of planar transformer parasitics using design of experiment methodology," 23rd Canadian Conference on Electrical and Computer Engineering, (CCECE) pp.1-5, 2-5 May 2010.

[8] Shahabi, N.; Zare, F.; Ghosh, A.; Ledwich, G.; "A new configuration for planar magnetic elements to reduce capacitive couplings," 14th International Power Electronics and Motion Control Conference, EPE/PEMC 2010, pp.T6-126-T6-130, 6-8 Sept. 2010.

[9] Morten Nymand, "High Efficiency Power Converter for Low Voltage High Power Applications", Danish Technical University, PhD Thesis, ISBN: 978-87-92465-33-7, pages: 164, 2010.

[10] Ziwei Ouyang; Sen, G.; Thomsen, O.C.; Andersen, M.A.E.; Björklund, T.; , "Fully integrated planar magnetics for primary-parallel isolated boost converter," Twenty-Sixth Annual IEEE Applied Power Electronics Conference and Exposition, APEC 2011, pp.174-181, 6-11 March 2011.

[11] Peng Xu; Mao Ye; Pit-Leong Wong; Lee, F.C.; , "Design of $48 \mathrm{~V}$ Voltage regulator modules with a novel integrated magnetics," IEEE Transactions on Power Electronics, vol.17, no.6, pp. 990-998, Nov 2002.

[12] Yi Wang; de Haan, S.W.H.; Ferreira, J.A.; , "Design of low-profile nanocrystalline transformer in high-current phase-shifted DC-DC converter," IEEE Energy Conversion Congress and Exposition, ECCE 2010, pp.2177-2181. 